\title{
Homodimericin A: A Complex Hexacyclic Fungal Metabolite
}

\section{Citation}

Mevers, Emily, Josep Saurí, Yizhou Liu, Arvin Moser, Timothy R. Ramadhar, Maria Varlan, R. Thomas Williamson, Gary E. Martin, and Jon Clardy. 2016. "Homodimericin A: A Complex Hexacyclic Fungal Metabolite." Journal of the American Chemical Society 138 (38): 12324-12327. doi:10.1021/jacs.6b07588. http://dx.doi.org/10.1021/jacs.6b07588.

\section{Published Version}

doi:10.1021/jacs.6b07588

\section{Permanent link}

http://nrs.harvard.edu/urn-3:HUL.InstRepos:34375281

\section{Terms of Use}

This article was downloaded from Harvard University's DASH repository, and is made available under the terms and conditions applicable to Other Posted Material, as set forth at http:// nrs.harvard.edu/urn-3:HUL.InstRepos:dash.current.terms-of-use\#LAA

\section{Share Your Story}

The Harvard community has made this article openly available.

Please share how this access benefits you. Submit a story.

\section{Accessibility}




\title{
Homodimericin A: A Complex Hexacyclic Fungal Metabolite
}

\author{
Emily Mevers, ${ }^{\dagger}$ Josep Saurí, ${ }^{\ddagger}$ Yizhou Liu, ${ }^{\ddagger}$ Arvin Moser, ${ }^{\S}$ Timothy R. Ramadhar, ${ }^{\dagger}$ Maria Varlan, ${ }^{\S}$ \\ R. Thomas Williamson, ${ }^{\ddagger}$ Gary E. Martin, ${ }^{\ddagger}$ and Jon Clardy ${ }^{* \dagger}$
}

${ }^{\dagger}$ Department of Biological Chemistry and Molecular Pharmacology, Harvard Medical School, 240 Longwood Avenue, Boston, Massachusetts 02115, United States

${ }^{\ddagger}$ Process Research and Development, NMR Structure Elucidation Group, Merck \& Co., Inc., Mail Stop RY800-C163, 126 East Lincoln Avenue, Rahway, New Jersey 07065 United States

${ }^{\S}$ Advanced Chemistry Development, Inc. (ACD/Laboratories) Toronto Department, 8 King Street East, Suite 107, Toronto, ON M5C 1B5, Canada

Supporting Information

ABSTRACT: Microbes sense and respond to their environment with small molecules, and discovering these molecules and identifying their functions informs chemistry, biology, and medicine. As part of a study of molecular exchanges between termite-associated actinobacteria and pathogenic fungi, we uncovered a remarkable fungal metabolite, homodimericin A, which is strongly upregulated by the bacterial metabolite bafilomycin $\mathrm{C} 1$. Homodimericin A is a hexacyclic polyketide with a carbon backbone containing eight contiguous stereogenic carbons in a $\mathrm{C}_{20}$ hexacyclic core. Only half of its carbon atoms have an attached hydrogen, which presented a significant challenge for NMR-based structural analysis. In spite of its microbial production and rich stereochemistry, homodimericin A occurs naturally as a racemic mixture. A plausible nonenzymatic reaction cascade leading from two identical achiral monomers to homodimericin $A$ is presented, and homodimericin A's formation by this path, a six-electron oxidation, could be a response to oxidative stress triggered by bafilomycin $\mathrm{C} 1$.

$\mathrm{B}$ acteria and fungi often compete for common substrates in a shared environment, and small-molecule exchanges typically mediate this competition. Identifying these small molecules and their functions provides essential information for chemical ecology and identifies small-molecule biological probes and potential therapeutic agents. We have been studying the molecular exchanges between bacteria and fungi in a variety of contexts, and a recent study of one such pair-Streptomyces sp. 4231 from a termite nest and Trichoderma harzianum WC13 from the same environment-uncovered a remarkable fungal metabolite, homodimericin A (1), which is the subject of this report.

As part of a larger study, we screened the interaction of a bacterial strain (Streptomyces sp. 4231) isolated from a Florida termite nest (Coptotermes formosanus) and an ecologically relevant fungal pathogen, the soil fungus $T$. harzianum. ${ }^{1}$ On a solid agar plate assay, Streptomyces sp. 4231 elicited the production of yellow pigments in nearby T. harzianum WC13 colonies (Figure S1), and the pigment mixture included 1, which is also produced by T. harzianum T22 (ATCC 20847).
Further studies established that the production of $\mathbf{1}$ is a direct response to the bacterially produced antifungal agent bafilomycin $\mathrm{Cl}^{2}$ but not bafilomycins $\mathrm{B} 1$ and $\mathrm{D}$, which are also produced by Streptomyces sp. 4231 (Figures S5 and S8).

Homodimericin A's molecular formula $\left(\mathrm{C}_{28} \mathrm{H}_{26} \mathrm{O}_{8}\right)$, based on ESI-QTOF data, indicated a severe proton deficiency and a challenging structural analysis. The ${ }^{13} \mathrm{C}$ NMR spectrum revealed five carbonyls with resonances between 194 and 201 $\operatorname{ppm}\left(\delta_{\mathrm{C}} 194.9,195.1,195.4,196.8\right.$, and 200.1$)$ and five olefins with 10 carbon resonances between 123 and $161 \mathrm{ppm}\left(\delta_{\mathrm{C}}\right.$ $123.6,125.6,129.3,130.4,131.6,135.7,138.0,140.1,158.7$, and 160.4), which accounted for 10 of the 16 degrees of unsaturation. Six rings account for the remaining six degrees of unsaturation. The ${ }^{1} \mathrm{H}$ NMR spectra revealed three vinyl methyls, one doublet methyl (1.75 ppm), two singlet methyls (1.69 and $1.82 \mathrm{ppm}$ ), and several olefinic protons between 5.70 and $6.50 \mathrm{ppm}$.

Analysis of routinely employed 2D NMR experiments (COSY, ME-PS-HSQC, HMBC, and ROESY) in conjunction with ACD/Laboratories Computer-Assisted Structure Elucidation (CASE) software ${ }^{3}$ identified three partial structures. The HMBC spectrum indicated pseudosymmetry within the molecule that was most clearly indicated by correlations of the two vinyl singlet methyls [9.9 (C14') and $9.6(\mathrm{C} 14) \mathrm{ppm}$. The two methyl groups had correlations to similar but distinct carbonyls [195.4 (C4') and 194.3 (C4) ppm, respectively] as well as a similar but distinct olefin $\left[123.6\left(\mathrm{C}^{\prime}\right) / 160.4\left(\mathrm{C}^{\prime}\right)\right.$ and $125.6(\mathrm{C} 3) / 158.7(\mathrm{C} 2) \mathrm{ppm}$, respectively], all of which are quaternary carbons. Comparing chemical shifts to a library of known compounds using the ACD/Structural Elucidator software $^{6}$ revealed that these shifts most likely belonged to two 2-hydroxy-3-methylbut-2-ene-1,4-dione moieties (Figure S20). The third fragment structure was a hexa-2,4-dienol, a group commonly seen in Trichoderma spp. metabolites. ${ }^{4,5}$ However, a thorough analysis of the ensemble of NMR experiments acquired thus far and processing by ACD/ Structure Elucidator software (Table S5) did not lead to a clearly defined planar structure for homodimericin A because of both its structural complexity-six rings linking 20 carbon

Received: July 22, 2016

Published: September 9, 2016 
atoms - and the indeterminate nature of the heteronuclear long-range coupling pathway of the HMBC correlations.

We then obtained a 1,1-HD-ADEQUATE spectrum ${ }^{7}$ optimized for ${ }^{1} J_{\mathrm{cc}}=40 \mathrm{~Hz}$, which in conjunction with the previously obtained $\mathrm{HMBC}$ data led to the complete planar assignment of homodimericin A (1) (Figure 1). Correlations in

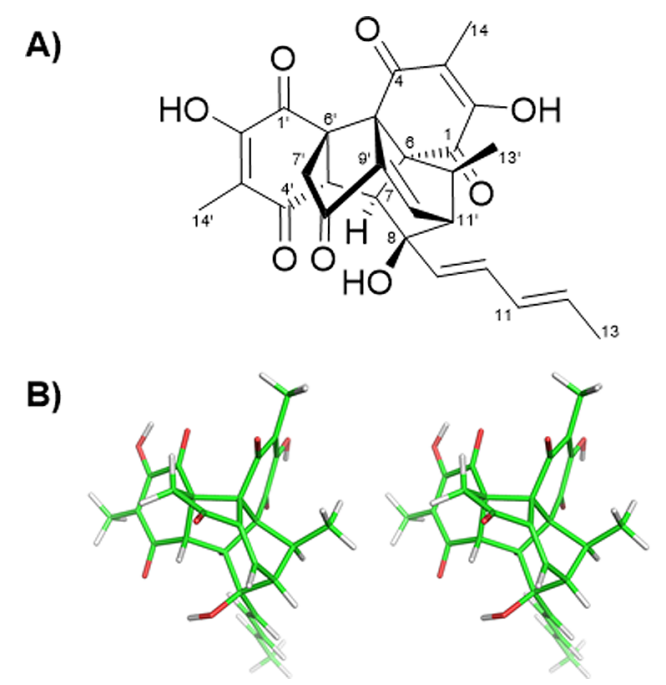

Figure 1. (A) 2D and (B) stereoview representations of homodimericin A (1).

the 1,1-HD-ADEQUATE spectrum arise from one-bond coupling of carbon pairs with proton detection and thus provides crucial two-bond connectivity. Correlations observed in the 1,1-HD-ADEQUATE spectrum of $\mathbf{1}$ yielded key information on the carbon-carbon connectivity of the four unassigned methines $\left(\mathrm{C} 7, \mathrm{C}^{\prime}, \mathrm{C}_{1} 1^{\prime}\right.$, and $\left.\mathrm{C} 12^{\prime}\right)$, three of which turned out to be bridgehead carbons, and each of their three substituents, in addition to the two substituents on the methylene (Figure 2). With the new data, the six rings were

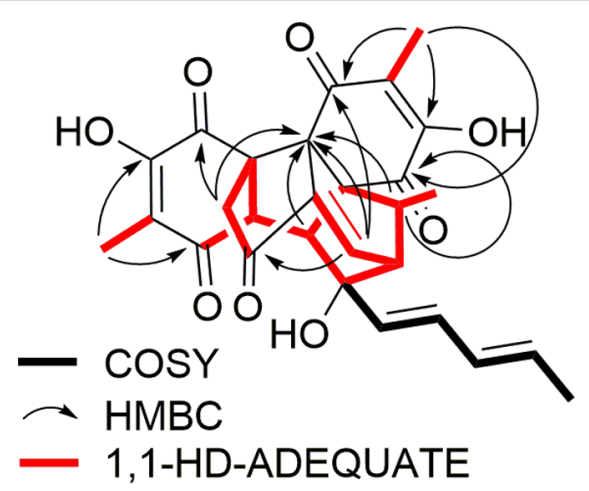

Figure 2. Key 2D NMR correlations for homodimericin A.

unequivocally set as three six-membered rings and three fivemembered rings. Two of the six-membered rings contained the 2-hydroxy-3-methylbut-2-ene-1,4-dione moieties previously identified, and the hexa-2,4-dienol tail moiety was attached to the five-membered ring containing $\mathrm{C} 8$, which also bears the hydroxyl group.

Inclusion of the 1,1-HD-ADEQUATE data in the ensemble of NMR data analyzed by the ACD/Structure Elucidator rendered the problem tractable and significantly reduced the number of potential candidates. These data reduced the number of isomers generated from 35394 to 4280 with six and two molecules, respectively, after passing filtering to remove duplicates and reduced the generation time from 32 min to $9 \mathrm{~s}$. The top candidate structure matched the planar structure assigned through manual interpretation of the data with a $\mathrm{d}_{\mathrm{N}}\left({ }^{13} \mathrm{C}\right)$ value of $3.51 \mathrm{ppm}$. Overall, the analysis strongly supported the planar structure of homodimericin A as shown in Figure 1: a hexacyclic polyketide with a carbon backbone containing 14 quaternary centers, including 11 consecutive quaternary carbons, in a $\mathrm{C}_{20}$ hexacyclic core.

Stereochemical analysis of homodimericin A (1) has straightforward and complex aspects. The straightforward ones arise largely from the constraints imposed by the polycyclic core and partly from noting that homodimericin A occurs as a racemic mixture, as shown by its lack of an observable Cotton effect in the circular dichroism spectrum (Figure S9). The complex polycyclic core fixes the relative configuration at $\mathrm{C} 5, \mathrm{C} 6, \mathrm{C}^{\prime}$, and $\mathrm{C}^{\prime} 1^{\prime}$ but leaves $\mathrm{C} 7, \mathrm{C} 8, \mathrm{C5}^{\prime}$, and $\mathrm{C}_{12}$ ' undetermined. To determine these four stereocenters, we combined multiple sources of experimental data, including ROEs, ${ }^{13} \mathrm{C}$ chemical shifts, two- and three-bond heteronuclear $J$ couplings, ${ }^{8}$ and anisotropic NMR data comprising residual dipolar couplings (RDCs) ${ }^{9,10}$ and residual chemical shift anisotropy (RCSA), ${ }^{11}$ with DFT structural modeling. ${ }^{12}$ By consideration of only diastereoisomeric candidates with the configurations at $\mathrm{C} 5, \mathrm{C} 6, \mathrm{C}^{\prime}$, and $\mathrm{C} 11^{\prime}$ fixed as $S, R, S$, and $R$, respectively (as drawn), possible candidates for homodimericin $\mathrm{A}$ can be labeled by their configurations at the unknown centers: $\mathrm{C} 7, \mathrm{C} 8, \mathrm{C} 5$ ', and $\mathrm{C} 12^{\prime}$. For example, the final configuration determined, as shown in Figure 1 , is represented by $7 S, 8 R, 5^{\prime} S, 12^{\prime} S$ (SRSS hereafter). In principle, one needs to consider 16 different diastereoisomers, but in practice, because of the multiple constraints imposed by the polycyclic core structure, not all of the combinatorial possibilities need be considered. For example, an ROE correlation between $\mathrm{H}^{\prime}$ and one of the $\mathrm{H}^{\prime}$ methylene protons suggests that $\mathrm{H}^{\prime}$ ' should point "up", which assigns $\mathrm{C5}^{\prime}$ as $S$. Assigning $\mathrm{C5}^{\prime}$ as $S$ also fixes the configuration of $\mathrm{C7}^{\prime}$ as $S$ since the $C 5^{\prime} S / C 7^{\prime} R$ combination does not lead to a reasonable model. A second example is generated by the ROE correlation observed between the $13^{\prime}$ and 14 methyl protons, which can be explained only if the $\mathrm{C} 13^{\prime}$ methyl is "up", requiring $\mathrm{C} 12^{\prime}$ to be $S$. Assigning $C 12^{\prime}$ as $R$ puts the two methyls $>5 \AA$ apart on the basis of DFT modeling. Further evidence is provided by the unusual upfield shift of the $13^{\prime}$ methyl at $0.71 \mathrm{ppm}$ due to shielding in the $S$ configuration but not in the $R$ configuration.

As an orthogonal stereochemical validation, we employed $\mathrm{RDC}^{9,10}$ and $\mathrm{RCSA}^{11}$ data to evaluate the goodness of fit for four diastereoisomers: SRSS, SRRS, SRSR, and RRRS. In our initial trial with all of the RDC and RCSA data included in the fitting with the lowest-free-energy conformers from DFT, we noticed that the diene tail, connected to the core via C8, was inaccurately placed by DFT geometry optimization since neither C8R nor C8S led to satisfactory agreement even when tail mobility was taken into consideration through ensemble fitting. We temporarily ignored the C8 stereochemistry, fixing it as $R$, and then used RDC and RCSA data to determine the other stereogenic centers within the core. Among the four diastereoisomers, SRSS has by far the lowest $Q$ factor of 0.162 , with the next lowest $Q$ factor, 0.329 , found for the SRSR configuration (Figure 3). The other two diastereoisomers have still higher $Q$ factors. 

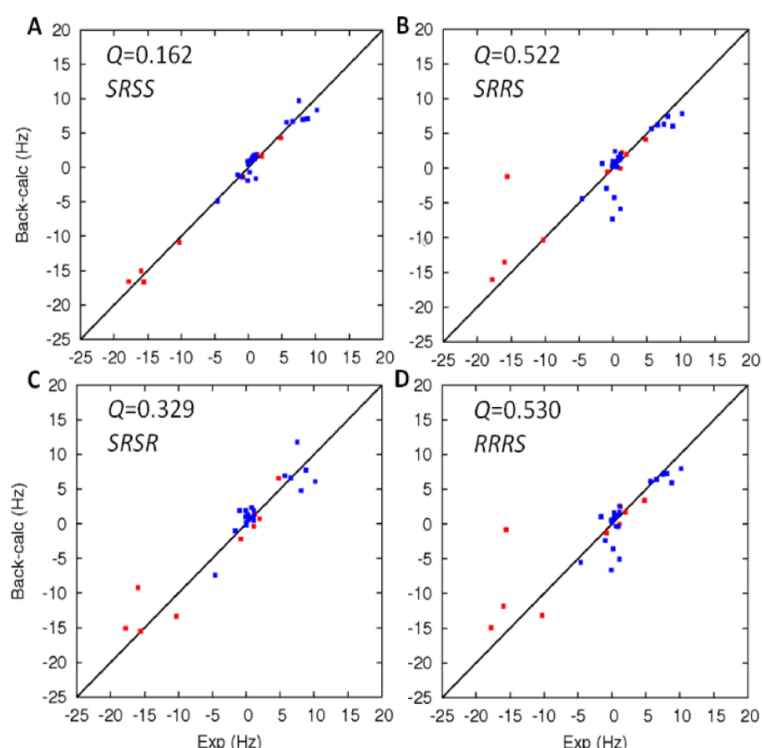

Figure 3. Correlation plots of experimental RDC (red) and RCSA (blue) values with back-predicted values from DFT models. Diastereoisomer SRSS has a much lower $Q$ factor (A) than diastereoisomers $S R R S, S R S R$, and RRRS (B-D).

The most difficult issue in the stereochemical analysis was the configuration at C8. ROE data were equivocal; RDC and RCSA data were complicated by tail positions in the DFT models. However, $\mathrm{C} 8$ was assigned through $J$-based configuration analysis (JBCA) $)^{8}$ as $R$ in conjunction with DFT calculations. C8R contains two low-energy rotamers that should exhibit ${ }^{3} J_{\mathrm{CH}}$ coupling constants from $\mathrm{H} 7-\mathrm{C} 9$ of 4.5 and $6.0 \mathrm{~Hz}$ and from $\mathrm{H}_{11}{ }^{\prime}-\mathrm{C} 9$ of 1.9 and $2.7 \mathrm{~Hz}$. In contrast, for C8S the corresponding two rotamers from $\mathrm{H} 7-\mathrm{C} 9$ were calculated to be 0.1 and $0.1 \mathrm{~Hz}$, and for $\mathrm{H} 11^{\prime}-\mathrm{C} 9$ they were expected to be 0.2 and $0.4 \mathrm{~Hz}$. In a selective HSQMBC IPAP experiment, ${ }^{13,14}$ the measured $\mathrm{H} 7-\mathrm{C} 9$ coupling was $5.1 \mathrm{~Hz}$ while the $\mathrm{H} 11^{\prime}-\mathrm{C} 9$ coupling was $2.2 \mathrm{~Hz}$, establishing the configuration as $\mathrm{C} 8 \mathrm{R}$.

Finally, with the relative configuration determined, we refined the diene tail orientation on the basis of RDC/RCSA data, ROE data, and the free energy landscape from DFT calculations (see the Supporting Information). The two tail olefin bonds both have $E$ configurations, and as a result, all four
$\mathrm{C}-\mathrm{H}$ bond vectors and ${ }^{13} \mathrm{C} \mathrm{CSA}$ tensors are parallel, giving rise to identical and redundant RDC and RCSA values. However, in combination with ROE data and DFT calculations, we were able to establish a dominant conformer with an $\mathrm{O}-\mathrm{C} 8-\mathrm{C} 9-$ C10 dihedral angle of $100^{\circ}$.

The racemic nature of $\mathbf{1}$ suggests that the key dimerization and cyclization steps in its biosynthesis occur spontaneously in situ in a manner somewhat similar to the proposed biosynthesis of $( \pm)$-epicolactone produced by the endophytic fungal species Epicoccum. ${ }^{15,16}$ A plausible scheme for the generation of $\mathbf{1}$ commences with the formation of aryltriol heptaketide $\mathbf{2}$ through a polyketide synthase pathway (Scheme 1). ${ }^{17}$ Oxidation of 2 affords 1,4-benzoquinoid 3, which subsequently homodimerizes through a Michael addition to form adduct 4 . This transformation involves $\gamma$-addition of the conjugated enol in monomer 3-A to the disubstituted endocyclic olefinic center bearing the triene in monomer 3-B. An intramolecular Michael addition involving 4 to form the internal cyclopentenyl ring in 6 is less likely, as it would involve a Baldwin-disfavored neutral 5(enolexo)-endo-trig cyclization. ${ }^{18,19}$ Alternatively, aromatization of 4 generates benzylic carbocation intermediate 5 , which can undergo a cationic cyclization that establishes a fluorenylrelated system in $\mathbf{6}$ where the pendant cyclopentenyl hydrogen and alkenyl/keto groups have a cis stereoconfiguration. Oxidation of 6 to benzoquinoid 7 enables an intramolecular endo-selective Diels-Alder reaction with the pendant heptatrienol unit followed by keto-enol tautomerization to generate pentacyclic 8. The sequence concludes with an intramolecular 5-exo-trig Prins cyclization of $\mathbf{8}$, where the cyclization event produces transient secondary carbocation 9 that undergoes a deprotonation involving the neighboring pseudoaxial hydrogen to furnish ( \pm )-homodimericin A (1). Although efforts to identify $\mathbf{2}$ in the chemical extract of T. harzianum have so far been unsuccessful, this outcome was not unexpected given its likely propensity to oxidize. In a related system, it took over 20 years to identify sorbicillinol, a structurally related polyketide that is a component of all sorbicillinoid-related metabolites. ${ }^{20,21}$

The dramatic upregulation of homodimericin A (1) production caused by bafilomycin $\mathrm{C} 1$ argues that it fulfills a functional role, but diverse antifungal and antibacterial assays have failed to identify any significant activity. Homodimericin A's lack of antibiotic activity points to a model in which homodimericin A plays a defensive, not an offensive, role in the

Scheme 1. Proposed Mechanism of Formation of Homodimericin A via a Cascade of Nonenzymatic Reactions

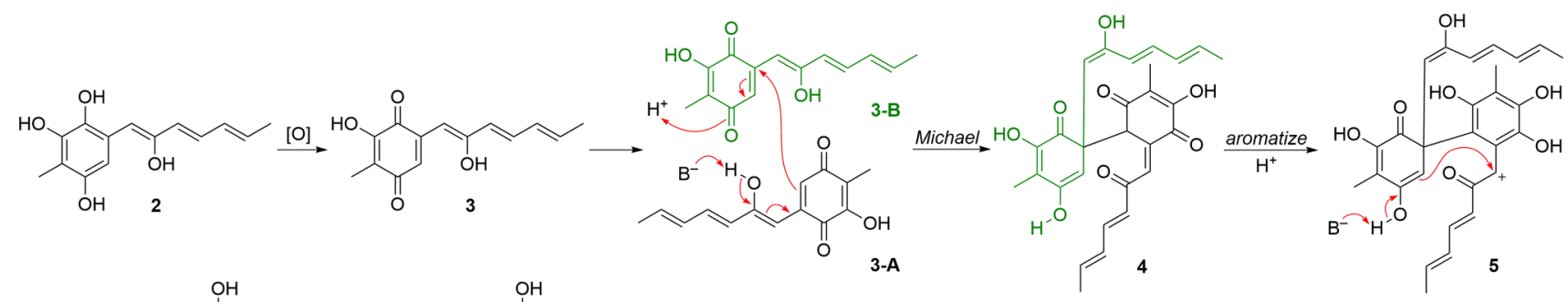

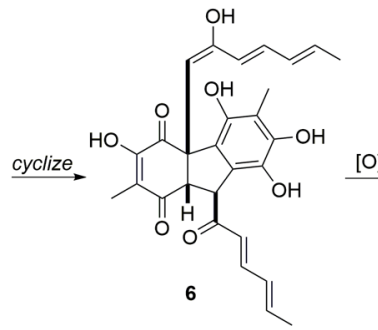

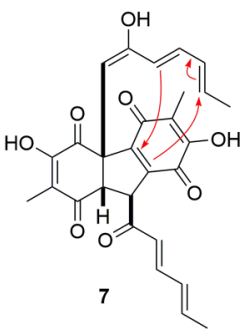
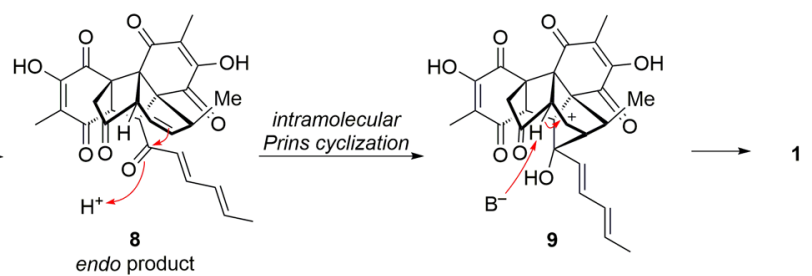
competition-that it may be a matter of what homodimericin A production does rather than what homodimericin A itself does. Bafilomycin $\mathrm{C} 1$ is a potent V-ATPase inhibitor, and fungal VATPases are well-known to play a critical role in maintaining cytosolic $\mathrm{pH}$ homeostasis. ${ }^{2,22}$ More recently, additional roles in oxidative stress resistance in yeast and human cells have been identified. $^{23}$ This oxidative stress role suggests a model in which the reactive oxygen species generated by bafilomycin $\mathrm{Cl}^{\prime} \mathrm{s}$ inhibition of V-ATPases are removed through the conversion of two hydroquinone monomers (2) to homodimericin A (1) in an overall six-electron oxidation that involves no enzymecatalyzed steps. In this model, homodimericin $\mathrm{A}$ is the biologically inert aftermath of a fungal counter to a bacterial attack-it is the biological equivalent of a spent sacrificial anode rather than an antibacterial agent. It will be interesting to see whether this proposal can be confirmed with laboratory studies.

\section{ASSOCIATED CONTENT}

\section{S Supporting Information}

The Supporting Information is available free of charge on the ACS Publications website at DOI: 10.1021/jacs.6b07588.

Experimental methods, images of the binary assays, MS chromatograms, NMR analysis, and Cartesian coordinates of $\mathbf{1}$ (PDF)

Case 2 full candidate list (PDF)

Case 3 full candidate list (PDF)

Case 4 full candidate list (PDF)

\section{AUTHOR INFORMATION}

\section{Corresponding Author}

*jon_clardy@hms.harvard.edu

\section{Notes}

The authors declare no competing financial interest.

\section{ACKNOWLEDGMENTS}

This work was funded by NIH (R01 GM086258 and U19 AI109673). We thank Thomas Chouvenc and Nan-Yao Su at the University of Florida Institute of Food and Agricultural Sciences for providing Streptomyces sp. 4231 and T. harzianum WC13. We also thank the Harvard Faculty of Science Small Molecule Mass Spectrometry Facility and the Harvard Medical School Center for Macromolecular Interactions for analytical services.

\section{REFERENCES}

(1) Chouvenc, T.; Efstathion, C. A.; Elliott, M. L.; Su, N.-Y. Proc. R. Soc. London, Ser. B 2013, 280, 20131885.

(2) Werner, G.; Hagenmaier, H.; Albert, K.; Kohlshorn, H. Tetrahedron Lett. 1983, 24, 5193-5196.

(3) Elyashberg, M. E.; Williams, A. J.; Martin, G. E. Prog. Nucl. Magn. Reson. Spectrosc. 2008, 53, 1-104.

(4) Reino, J. L.; Guerrero, R. F.; Hernández-Galán, R.; Collado, I. G. Phytochem. Rev. 2008, 7, 89-123.

(5) Harned, A. M.; Volp, K. A. Nat. Prod. Rep. 2011, 28, 1790-1810.

(6) ACD/Structure Elucidator, version 14.04; Advanced Chemistry Development: Toronto, ON, 2015; www.acdlabs.com.

(7) Saurí, J.; Bermel, W.; Buevich, A. V.; Sherer, E. C.; Joyce, L. A.; Sharaf, M. H. M.; Schiff, P. L.; Parella, T.; Williamson, R. T.; Martin, G. E. Angew. Chem., Int. Ed. 2015, 54, 10160-10164.

(8) Matsumori, N.; Kaneno, D.; Murata, M.; Nakamura, H.; Tachibana, K. J. Org. Chem. 1999, 64, 866-876.

(9) Kummerlöwe, G.; Luy, B. Annu. Rep. Nucl. Magn. Reson. Spectrosc. 2009, 68, 193-232.
(10) Gil, R. R.; Griesinger, C.; Navarro-Vazquez, A.; Sun, H. In Structure Elucidation in Organic Chemistry: The Search for the Right Tools; Cid, M.-M., Bravo, J., Eds.; Wiley-VCH: New York, 2015; pp 279-323.

(11) Nath, N.; Schmidt, M.; Gil, R. R.; Williamson, R. T.; Martin, G. E.; Navarro-Vázquez, A.; Griesinger, C.; Liu, Y. J. Am. Chem. Soc. 2016, $138,9548-9556$.

(12) Frisch, M. J.; Trucks, G. W.; Schlegel, H. B.; Scuseria, G. E.; Robb, M. A.; Cheeseman, J. R.; Scalmani, G.; Barone, V.; Mennucci, B.; Petersson, G. A.; Nakatsuji, H.; Caricato, M.; Li, X.; Hratchian, H. P.; Izmaylov, A. F.; Bloino, J.; Zheng, G.; Sonnenberg, J. L.; Hada, M.; Ehara, M.; Toyota, K.; Fukuda, R.; Hasegawa, J.; Ishida, M.; Nakajima, T.; Honda, Y.; Kitao, O.; Nakai, H.; Vreven, T.; Montgomery, J. A., Jr.; Peralta, J. E.; Ogliaro, F.; Bearpark, M.; Heyd, J. J.; Brothers, E.; Kudin, K. N.; Staroverov, V. N.; Kobayashi, R.; Normand, J.; Raghavachari, K.; Rendell, A.; Burant, J. C.; Iyengar, S. S.; Tomasi, J.; Cossi, M.; Rega, N.; Millam, J. M.; Klene, M.; Knox, J. E.; Cross, J. B.; Bakken, V.; Adamo, C.; Jaramillo, J.; Gomperts, R.; Stratmann, R. E.; Yazyev, O.; Austin, A. J.; Cammi, R.; Pomelli, C.; Ochterski, J. W.; Martin, R. L.; Morokuma, K.; Zakrzewski, V. G.; Voth, G. A.; Salvador, P.; Dannenberg, J. J.; Dapprich, S.; Daniels, A. D.; Farkas, Ö.; Foresman, J. B.; Ortiz, J. V.; Cioslowski, J.; Fox, D. J. Gaussian 09; Gaussian, Inc.: Wallingford, CT, 2009.

(13) Saurí, J.; Espinosa, J. F.; Parella, T. Angew. Chem., Int. Ed. 2012, 51, 3919-3922.

(14) Gil, S.; Espinosa, J. F.; Parella, T. J. Magn. Reson. 2011, 213, 145-150.

(15) Talontsi, F. M.; Dittrich, B.; Schuffler, A.; Sun, H.; Laatsch, H. Eur. J. Org. Chem. 2013, 2013, 3174-3180.

(16) Ellerbrock, P.; Armanino, N.; Ilg, M. K.; Webster, R.; Trauner, D. Nat. Chem. 2015, 7, 879-882.

(17) Dewick, P. M. In Medicinal Natural Products; John Wiley \& Sons: Chichester, U.K., 2009; Vol. 3, pp 39-135.

(18) Baldwin, J. E.; Cutting, J.; Dupont, W.; Kruse, L.; Silberman, L.; Thomas, R. C. J. Chem. Soc., Chem. Commun. 1976, 736-738.

(19) Baldwin, J. E. J. Chem. Soc., Chem. Commun. 1976, 734-736.

(20) Abe, N.; Sugimoto, O.; Tanji, K.-i.; Hirota, A. J. Am. Chem. Soc. 2000, 122, 12606-12607.

(21) Abe, N.; Sugimoto, O.; Arakawa, T.; Tanji, K.-i.; Hirota, A. Biosci., Biotechnol., Biochem. 2001, 65, 2271-2279.

(22) Drose, S.; Altendorf, K. J. Exp. Biol. 1997, 200, 1-8.

(23) Kane, P. M. J. Bioenerg. Biomembr. 2007, 39, 415-421. 